\title{
PAU-BRASIL (Caesalpinia echinata LAM., LEGUMINOSAE) NA ARBORIZAÇÃO URBANA DE SÃO PAULO (SP), RIO DE JANEIRO (RJ) E RECIFE (PE)1
}

\author{
Yuri Tavares Rocha ${ }^{2} \&$ Adeliana Saes Coelho Barbedo $^{3}$ \\ (recebido em 28.02.2008 e aceito para publicação em 07.06.2008)
}

\begin{abstract}
RESUMO
As grandes cidades apresentam sérios problemas, principalmente quando os componentes naturais não são considerados em seu planejamento. A vegetação exerce grande influência sobre o ambiente urbano. Além disso, a presença de árvores nativas na arborização pode ser uma das estratégias para conservação ex situ. O pau-brasil (Caesalpinia echinata Lam. - Leguminosae) é uma espécie em perigo de extinção e, por seu valor histórico, é a árvore nacional. Sua presença na cidade pode ser uma forma de manter a relação entre o brasileiro e a árvore nacional, aliando-se as funções benéficas da arborização urbana, mitigadoras da artificialidade desse ambiente. Realizaram-se pesquisas em São Paulo (SP), Rio de Janeiro (RJ) e Recife (PE), que objetivaram: constatar o uso na arborização urbana; registrar dados sobre os exemplares encontrados; e verificar sua adaptação ao ambiente urbano.
\end{abstract}

Palavras-chave: pau-brasil, arborização urbana, São Paulo, Rio de Janeiro, Recife

\footnotetext{
${ }^{1}$.Pesquisa integrante do Projeto Temático Pau-brasil (www.paubrasilvirutal.bio.br), financiado pela Fundação de Amparo à Pesquisa do Estado de São Paulo (Fapesp)

${ }^{2}$.Engenheiro Agrônomo, Professor Doutor, Departamento de Geografia, Faculdade de Filosofia, Letras e Ciências Humanas, Universidade de São Paulo, São Paulo (SP). E-mail: yuritr@usp.br

${ }^{3}$.Engenheira Agrônoma, Doutora, Divisão Técnica de Produção, Departamento de Parques e Áreas Verdes, Secretaria do Verde e do Meio Ambiente, Prefeitura do Município de São Paulo, São Paulo (SP). E-mail: adeliana.barbedo@gmail.com
} 


\title{
BRAZILWOOD (Caesalpinia echinata LAM. - LEGUMINOSAE) IN URBAN ARBORIZATION IN SÃO PAULO (SP), RIO DE JANEIRO (RJ) AND RECIFE (PE)
}

\begin{abstract}
Great cities usually have serious problems related to the presence of natural components, mainly when they are not considered in its urban plan. The vegetation is considered to have large influence on the urban environment. Moreover, the presence of native trees in the urban arborization can be one of the strategies for ex situ conservation of some species. Brazilwood is an endangered species, and for its historical value, it is considered a national tree, a symbol of Brazil. Brazilwood presence in urban environment may be a form to keep the relation between Brazilians and the national tree. We have been made researches in São Paulo (SP), Rio de Janeiro (RJ), and Recife (PE), with the goal to understand the importance of urban arborization, collect data about the subjects (Brazilwood), and verify the Brazilwood adaptation in urban environment.
\end{abstract}

Key words: brazilwood, urban arborization, São Paulo, Rio de Janeiro, Recife 


\section{INTRODUÇÃO}

Na história da humanidade, a agregação das famílias e a formação de comunidades, povoados, vilas e, finalmente, cidades, provocaram alterações no meio natural e originaram um ambiente diferente e peculiar, o urbano.

Atualmente, as grandes cidades apresentam sérios problemas em seu ambiente tais como inundações, instabilidade de vertentes, impermeabilização excessiva da superfície, etc., ignorando-se que a natureza e seus componentes ainda são importantes para o entendimento desse ambiente peculiar, para seu planejamento e seu conseqüente equilíbrio e harmonia. Um desses componentes de grande relevância é a vegetação, principalmente representada pelas árvores.

A vegetação exerce grande influência sobre os fatores ambientais do meio urbano; além disso, a vegetação também pode servir como indicador biológico de qualidade ambiental das cidades, como por exemplo a presença de liquens e epífitas nas árvores urbanas (CAVALHEIRO, 1991).

Além disso, a vegetação nas cidades também pode ser um elemento purificador da atmosfera urbana, fixando partículas suspensas e gases; produtor de microclimas mais agradáveis aos citadinos; e, protetor contra os ruídos urbanos, tais como fundo sonoro contínuo e ruídos descontínuos produzidos pelas atividades urbanas (RODRÍGUEZ-AVIAL LLARDENT, 1982).

O homem sempre foi ligado à existência das árvores e explorou seus recursos; "é com elas que sombreamos e embelezamos as largas avenidas e ruas" das cidades, que devem ter "espaço para parques e jardins públicos, para que um pouco da flora e fauna esteja acessível aos seus habitantes e contribua para amenizar-lhes a existência e satisfazer esse anseio da sua natureza" (HOEHNE, 1943).

Pode-se considerar a arborização como "um processo sistemático de organização da paisagem a partir da introdução ordenada de espécies de porte arbóreo estando o mesmo condicionado a fatores de ordem funcional, estética, ambiental e sócio-cultural; (...) também está atrelada às características morfológicas e tipológicas próprias de cada espécie. Seu uso pode estar delimitado pela malha urbana, ocupando áreas livres públicas como ruas, praças, áreas litorâneas, e podendo ainda ser estendido às reservas florestais dentro do limite da área urbana" (TERRA et al., 2004).

No mundo atual, "é necessário valorizar e preservar nossa fauna e flora, considerando o plantio de espécies nativas na arborização de nossas cidades como um dos caminhos para esta valorização, porque assim estará dando um caráter particular a cada região, evidenciando sua flora" (TERRA et al., 2004). No Brasil, o artista plástico e 
paisagista Roberto Burle Marx foi um dos pioneiros a utilizar espécies arbóreas nativas brasileiras em projetos paisagísticos e de arborização urbana (MELLO FILHO, 2000).

A presença de árvores nativas na arborização urbana pode ser uma das estratégias para sua conservação, já que é um modo simples, barato e efetivo para espécies nativas que podem ser introduzidas no comércio horticultural (RAVEN, 1976). Swietenia humilis Zucc. é um exemplo de uma espécie arbórea tropical e ornamental utilizada na arborização urbana; essa espécie nativa do Panamá estava virtualmente desaparecida de seu ambiente natural (terras baixas panamenhas) e passou a ser uma árvore muito comum nas ruas próximas ao Canal do Panamá (FRANKEL; SOULÉ, 1992).

Populações nativas de pau-brasil (Caesalpinia echinata Lam. - Leguminosae), a ibirapitanga dos índios, eram encontradas desde o estado do Rio de Janeiro até o Rio Grande do Norte (ROCHA, 2005). Por causa de sua madeira fornecer corante vermelho, utilizado para tingir tecidos, essas populações foram intensamente exploradas, ocorrendo concomitantemente redução de área da própria Mata Atlântica (ROCHA, 2004b). Hoje, com maior preocupação com a conservação de fragmentos florestais desse domínio e de populações nativas dessa espécie, há importantes iniciativas de conservação in situ nos estados de sua ocorrência natural como de conservação ex situ no estado de São Paulo (ROCHA et al. 2003; ROCHA, 2004a).

Além de o pau-brasil ser uma espécie arbórea do domínio brasileiro da Floresta Atlântica em perigo de extinção (Portaria IBAMA n.37-N, de 3 de abril de 1992), é considerado a árvore nacional por seu valor histórico e simbólico em nossa cultura, cuja comemoração é no dia 3 de maio (Lei Federal n.6.607 de 7 de dezembro de 1978). Contudo, vale ressaltar que, a flor símbolo do Brasil é o ipê.

Sua presença no meio urbano pode ser uma maneira de preservar a relação entre o brasileiro e sua árvore nacional, iniciada nos primórdios de nossa colonização, aliando-se tanto as funções benéficas da arborização urbana, mitigadoras da artificialidade intrínseca ao ambiente construído, quanto os valores simbólico e histórico, que devem ser resgatados e cultivados de forma consciente e não simplesmente ufanista.

O pau-brasil na arborização das cidades, mesmo naquelas fora da área de ocorrência natural, pode ser uma das maneiras de conservação ex situ da variabilidade genética intra-específica de Caesalpinia echinata, espécie na lista das ameaçadas de extinção.

A seguir, relatam-se as pesquisas realizadas em São Paulo (SP), que está fora da área de ocorrência natural do pau-brasil, e também as realizadas em duas cidades da área de ocorrência natural do pau-brasil, Rio de Janeiro (RJ) e Recife (PE), que objetivaram constatar o uso da espécie na arborização urbana, registrar as informações sobre os exemplares encontrados e verificar sua adaptação ao ambiente urbano. 


\section{MATERIAIS E MÉTODOS}

Em primeiro lugar, as cidades foram selecionadas na seguinte maneira:

- São Paulo (SP): apesar de não estar na área de ocorrência natural do pau-brasil, é a cidade-sede da equipe de pesquisa e possui grande quantidade de árvores em sua arborização urbana, com probabilidade de se localizar exemplares de pau-brasil, além de se poder constatar se as árvores se desenvolvem satisfatoriamente fora da área de ocorrência natural (diferente latitude, altitude, clima, solo, etc.);

- Rio de Janeiro (RJ): está no estado que é o limite sul da área de ocorrência natural do pau-brasil e se teve a oportunidade de realizar trabalho de campo nessa cidade, além de se poder constatar sua adaptação ao meio urbano dentro da área de ocorrência natural;

- Recife (PE): está num estado próximo ao limite norte da área de ocorrência natural do pau-brasil (Rio Grande do Norte) e se teve a oportunidade de realizar trabalho de campo nessa cidade, além de se poder constatar sua adaptação ao meio urbano dentro da área de ocorrência natural.

Ressalta-se ainda que existem poucas metodologias para o levantamento de espécies arbóreas no meio urbano em cidades tropicais, sendo os primeiros trabalhos brasileiros os realizados por MILANO (1984), LIMA (1993) e BRASIL (1994), entre outros.

A maioria das cidades brasileiras, tais como São Paulo, Rio de Janeiro e Recife não possui um cadastro ou inventário dos indivíduos arbóreos existentes nas ruas, avenidas, praças e parques, muito menos a identificação das espécies, sua localização e freqüência de uso em arborização urbana. Por causa da falta desses bancos de dados, buscaram-se informações sobre a existência do pau-brasil nas ruas e avenidas das referidas cidades de diversas maneiras e, também, coletaram-se dados em diferentes níveis de detalhe.

Em São Paulo, buscaram-se informações sobre a existência do pau-brasil nas ruas e avenidas a partir de:

- Banco de dados do projeto Árvore Saudável, contrato celebrado entre o Instituto de Pesquisas Tecnológicas (IPT) e a Secretaria do Verde e do Meio Ambiente (SVMA) da Prefeitura do Município de São Paulo (PMSP), por meio do Departamento de Parques e Áreas Verdes (DEPAVE), realizado em diversos bolsões da cidade, em especial distritos considerados patrimônio ambiental e com grande ocorrência de queda de árvores nos últimos anos;

- Conhecimento empírico de técnicos do DEPAVE;

- Bibliografia relacionada à vegetação considerada patrimônio ambiental e imune a corte da cidade de São Paulo, em especial a publicação "Vegetação Significativa do Município de São Paulo" (SÃO PAULO, 1998). 
Para o levantamento realizado em São Paulo, a metodologia adotada foi aquela do projeto "Árvore Saudável", constituída de levantamento detalhado da situação de cada árvore de pau-brasil encontrada, preenchendo-se formulário de 67 campos com os seguintes dados coletados em campo: data, responsável, logradouro, subprefeitura, distrito, bairro, número do imóvel, distância da esquina, distância do alinhamento do lote, referência do logradouro transversal anterior, latitude, longitude, tipo de via, tipo de edificação, localização, localização no passeio público, alinhamento e ou guia, largura do passeio, tipo de pavimento, levantamento do pavimento, tipo de calçada verde, tipo de canteiro, largura, comprimento, diâmetro e área do canteiro, presença de vegetação interferente, presença de protetor/tutor, área permeável (largura, comprimento e diâmetro), presença de árvore morta, gênero, epíteto, família, nome científico, nome popular, porte potencial estimado, diâmetro a altura do peito (DAP) potencial estimado, coleta de exsicata, origem da muda, perímetro do colo, diâmetro do colo, perímetro a altura do peito, diâmetro a altura do peito, altura da primeira bifurcação, altura da árvore, diâmetro da copa, inclinação, interferências no sistema radicular, no tronco e na copa, diagnóstico do sistema radicular, do colo, do tronco e da copa, sanidade biológica do sistema radicular, do colo, do tronco e da copa observações fenológicas, situação da árvore, estado geral, risco de queda e recomendações de manejo. Além disso, todas as árvores foram fotografadas e catalogadas por um número de identificação composto pelo número de cadastro do logradouro (CADLOG) e pelo número seqüencial da árvore no logradouro.

Por essa metodologia demandar um maior tempo de coleta de dados em campo e de ser mais adequado para as árvores presentes em ruas e avenidas, decidiu-se não realizar o levantamento de árvores de pau-brasil existentes em áreas verdes públicas de São Paulo (praças e parques). No Rio de Janeiro e em Recife, foram coletados apenas dados de coordenadas geográficas, altitude, altura estimada, fenologia e fotografias dos exemplares localizados em ruas e avenidas e, também, em praças e parques públicos, pela exiguidade de tempo para o trabalho de campo..

Para se obter informações sobre a utilização e localização de exemplares de paubrasil na arborização da cidade do Rio de Janeiro (RJ), fizeram-se reuniões com técnicos da Fundação de Parques e Jardins (FPJ), da Secretaria do Meio Ambiente da Prefeitura Municipal do Rio de Janeiro.

Para se obter essas mesmas informações em Recife (PE), fez-se reunião com técnicos do Departamento de Praças e Áreas Verdes da Empresa de Limpeza Urbana (Emlurb), da Prefeitura Municipal de Recife, e com técnicos da Diretoria de Meio Ambiente da Secretaria Municipal de Planejamento, Urbanismo e Meio Ambiente. 


\section{RESULTADOS E DISCUSSÃO}

\section{São Paulo (SP)}

Em São Paulo, foram registradas 35 árvores de pau-brasil, distribuídas em 19 logradouros públicos pertencentes a dez subprefeituras paulistanas (Tabela 1 e Figura 1), localizadas nas mais diferentes situações, desde áreas estritamente residenciais (Figuras 2 e 3) até ruas e avenidas de tráfego intenso de veículos (Figuras 4 e 5).

Tabela 1: Relação dos indivíduos de pau-brasil registrados em São Paulo (SP)

\begin{tabular}{|c|c|c|c|c|}
\hline Indivíduo & Logradouro & N. do imóvel & Latitude (S) & Longitude (W) \\
\hline 1 & Rua Adelino Bertoli & 168 & $23^{\circ} 29^{\prime} 31,4^{\prime \prime}$ & $46^{\circ} 36^{\prime} 25,7^{\prime \prime}$ \\
\hline 2 & Rua Amadeu Amaral & - & $23^{\circ} 34^{\prime} 07,7^{\prime \prime}$ & $46^{\circ} 38^{\prime} 37,7^{\prime \prime}$ \\
\hline 3 & Rua Amadeu Amaral & - & $23^{\circ} 34^{\prime} 07,7^{\prime \prime}$ & $46^{\circ} 38^{\prime} 37,7^{\prime \prime}$ \\
\hline 4 & Rua Amadeu Amaral & - & $23^{\circ} 34^{\prime} 07,7^{\prime \prime}$ & $46^{\circ} 38^{\prime} 37,7^{\prime \prime}$ \\
\hline 5 & Rua Amadeu Amaral & - & $23^{\circ} 34^{\prime} 07,7^{\prime \prime}$ & $46^{\circ} 38^{\prime} 37,7^{\prime \prime}$ \\
\hline 6 & Rua Amadeu Amaral & - & $23^{\circ} 34^{\prime} 07,7^{\prime \prime}$ & $46^{\circ} 38^{\prime} 37,7^{\prime \prime}$ \\
\hline 7 & Rua Bauru & 335 & $23^{\circ} 32^{\prime} 52,7^{\prime \prime}$ & $46^{\circ} 40^{\prime} 07,1^{\prime \prime}$ \\
\hline 8 & Rua Cataguazes & 72 & $23^{\circ} 29^{\prime} 54,9^{\prime \prime}$ & $46^{\circ} 36^{\prime} 53,7^{\prime \prime}$ \\
\hline 9 & Rua Cataguazes & 387 & $23^{\circ} 29^{\prime} 45,1^{\prime \prime}$ & $46^{\circ} 36^{\prime} 52,2^{\prime \prime}$ \\
\hline 10 & Av. Santa Catarina & 400 & $23^{\circ} 38^{\prime} 23,3^{\prime \prime}$ & $46^{\circ} 40^{\prime} 06,8^{\prime \prime}$ \\
\hline 11 & Rua do Ceuta & 196 & $23^{\circ} 35^{\prime} 43,8^{\prime \prime}$ & $46^{\circ} 29^{\prime} 23,3^{\prime \prime}$ \\
\hline 12 & Rua do Ceuta & $222^{*}$ & $23^{\circ} 35^{\prime} 45,7^{\prime \prime}$ & $46^{\circ} 39^{\prime} 25,1^{\prime \prime}$ \\
\hline 13 & Rua do Ceuta & $222^{*}$ & $23^{\circ} 35^{\prime} 45,7^{\prime \prime}$ & $46^{\circ} 39^{\prime} 25,1^{\prime \prime}$ \\
\hline 14 & Rua Ernesto Nazaré & 374 & $23^{\circ} 33^{\prime} 30,7^{\prime \prime}$ & $46^{\circ} 42^{\prime} 15,9^{\prime \prime}$ \\
\hline 15 & Rua da Fraternidade & 630 & $23^{\circ} 38^{\prime} 40,2^{\prime \prime}$ & $46^{\circ} 41^{\prime} 36,5^{\prime \prime}$ \\
\hline 16 & Av. Eng. George Corbisier & $285^{\star \star}$ & $23^{\circ} 38^{\prime} 23,8^{\prime \prime}$ & $46^{\circ} 38^{\prime} 35,3^{\prime \prime}$ \\
\hline 17 & Rua Ilhéus & 358 & $23^{\circ} 32^{\prime} 53,2^{\prime \prime}$ & $46^{\circ} 40^{\prime} 30,2^{\prime \prime}$ \\
\hline 18 & Rua Joaquim Floriano & 466 & $23^{\circ} 35^{\prime} 04,9^{\prime \prime}$ & $46^{\circ} 40^{\prime} 31,1^{\prime \prime}$ \\
\hline 19 & Rua Joaquim Floriano & 466 & $23^{\circ} 35^{\prime} 05,0^{\prime \prime}$ & $46^{\circ} 40^{\prime} 31,3^{\prime \prime}$ \\
\hline 20 & Rua João Della Manna & 998 & $23^{\circ} 34^{\prime} 56,2^{\prime \prime}$ & $46^{\circ} 43^{\prime} 42,3^{\prime \prime}$ \\
\hline 21 & Rua João Julião & $331^{*}$ & $23^{\circ} 34^{\prime} 06,2^{\prime \prime}$ & $46^{\circ} 38^{\prime} 37,0^{\prime \prime}$ \\
\hline 22 & Rua João Julião & $331^{*}$ & $23^{\circ} 34^{\prime} 06,2^{\prime \prime}$ & $46^{\circ} 38^{\prime} 37,0^{\prime \prime}$ \\
\hline 23 & Av. Min. Laudo F. Camargo & 240 & $23^{\circ} 35^{\prime} 15,6^{\prime \prime}$ & $46^{\circ} 44^{\prime} 12,0^{\prime \prime}$ \\
\hline 24 & Rua Pau-brasil & 29 & $23^{\circ} 32^{\prime} 35,9^{\prime \prime}$ & $46^{\circ} 43^{\prime} 18,3^{\prime \prime}$ \\
\hline 25 & Rua Pau-brasil & 351 & $23^{\circ} 32^{\prime} 31,7^{\prime \prime}$ & $46^{\circ} 43^{\prime} 27,7^{\prime \prime}$ \\
\hline
\end{tabular}




\begin{tabular}{|c|c|c|c|c|}
\hline 26 & Rua Pau-brasil & 371 & $23^{\circ} 35^{\prime} 15,6^{\prime \prime}$ & $46^{\circ} 41^{\prime} 35,4^{\prime \prime}$ \\
\hline 27 & Rua Pau-brasil & 529 & $23^{\circ} 32^{\prime} 30,5^{\prime \prime}$ & $46^{\circ} 43^{\prime} 34,5^{\prime \prime}$ \\
\hline 28 & Rua Pau-brasil & 548 & $23^{\circ} 32^{\prime} 29,2^{\prime \prime}$ & $46^{\circ} 43^{\prime} 35,3^{\prime \prime}$ \\
\hline 29 & Rua Pau-brasil & 590 & $23^{\circ} 32^{\prime} 28,1^{\prime \prime}$ & $46^{\circ} 43^{\prime} 36,5^{\prime \prime}$ \\
\hline 30 & Rua Pau-brasil & 593 & $23^{\circ} 32^{\prime} 28,1^{\prime \prime}$ & $46^{\circ} 43^{\prime} 36,5^{\prime \prime}$ \\
\hline 31 & Rua Pedro & 111 & $23^{\circ} 27^{\prime} 47,1^{\prime \prime}$ & $46^{\circ} 37^{\prime} 05,5^{\prime \prime}$ \\
\hline 32 & Rua Peixoto Gomide & 1.896 & $23^{\circ} 34^{\prime} 05,3^{\prime \prime}$ & $46^{\circ} 39^{\prime} 51,5^{\prime \prime}$ \\
\hline 33 & Rua Senador Vergueiro & 555 & $23^{\circ} 38^{\prime} 40,6^{\prime \prime}$ & $46^{\circ} 41^{\prime} 32,3^{\prime \prime}$ \\
\hline 34 & Rua dos Zaparás & 97 & $23^{\circ} 33^{\prime} 30,2^{\prime \prime}$ & $46^{\circ} 41^{\prime} 35,4^{\prime \prime}$ \\
\hline 35 & Rua dos Zaparás & 215 & $23^{\circ} 33^{\prime} 27,1^{\prime \prime}$ & $46^{\circ} 41^{\prime} 38,6^{\prime \prime}$ \\
\hline
\end{tabular}

Obs.: * Numeração do imóvel estimada. ** Indivíduo localizado no canteiro central 


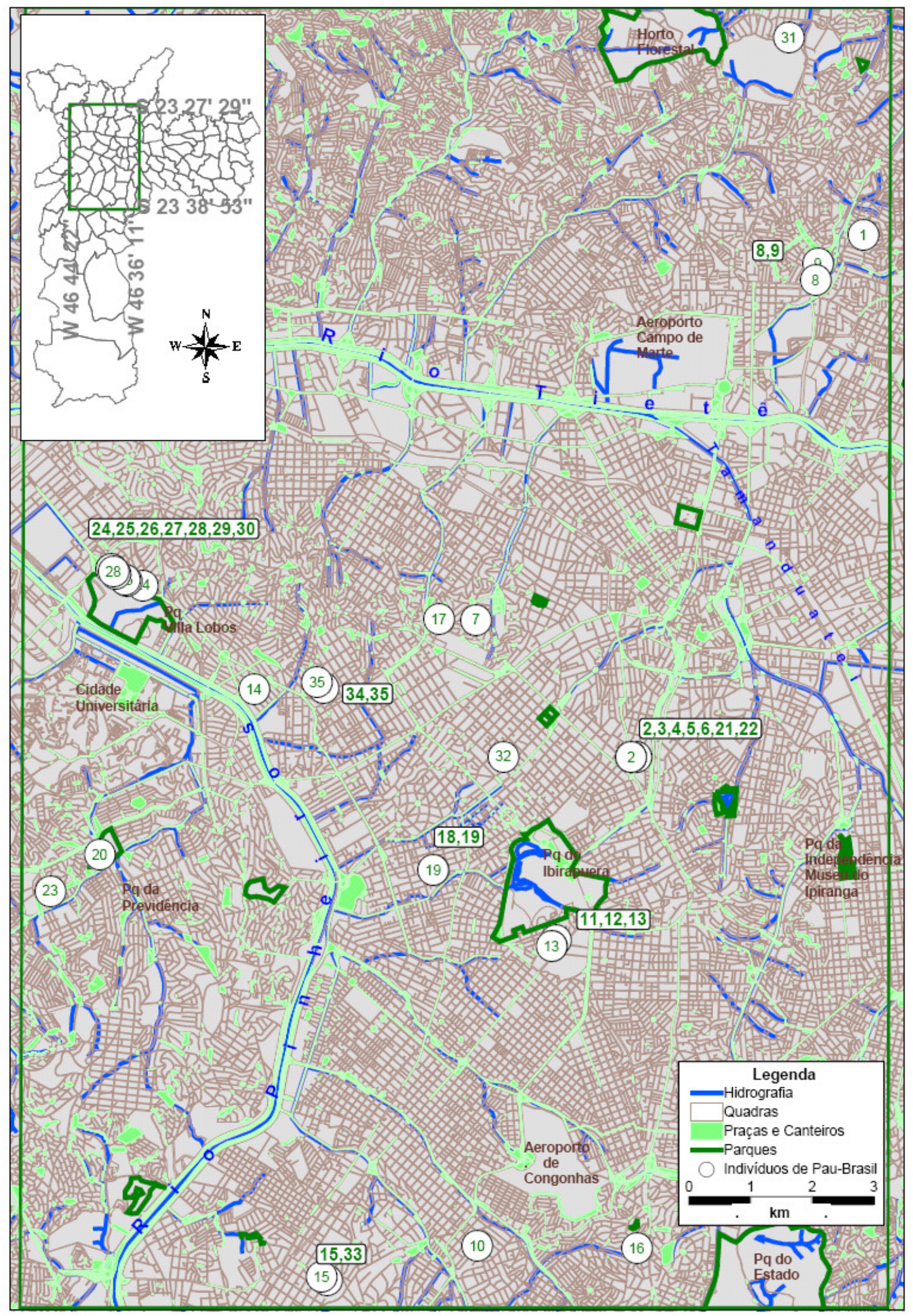

Figura 1: Localização dos indivíduos de pau-brasil registrados em São Paulo (SP) 


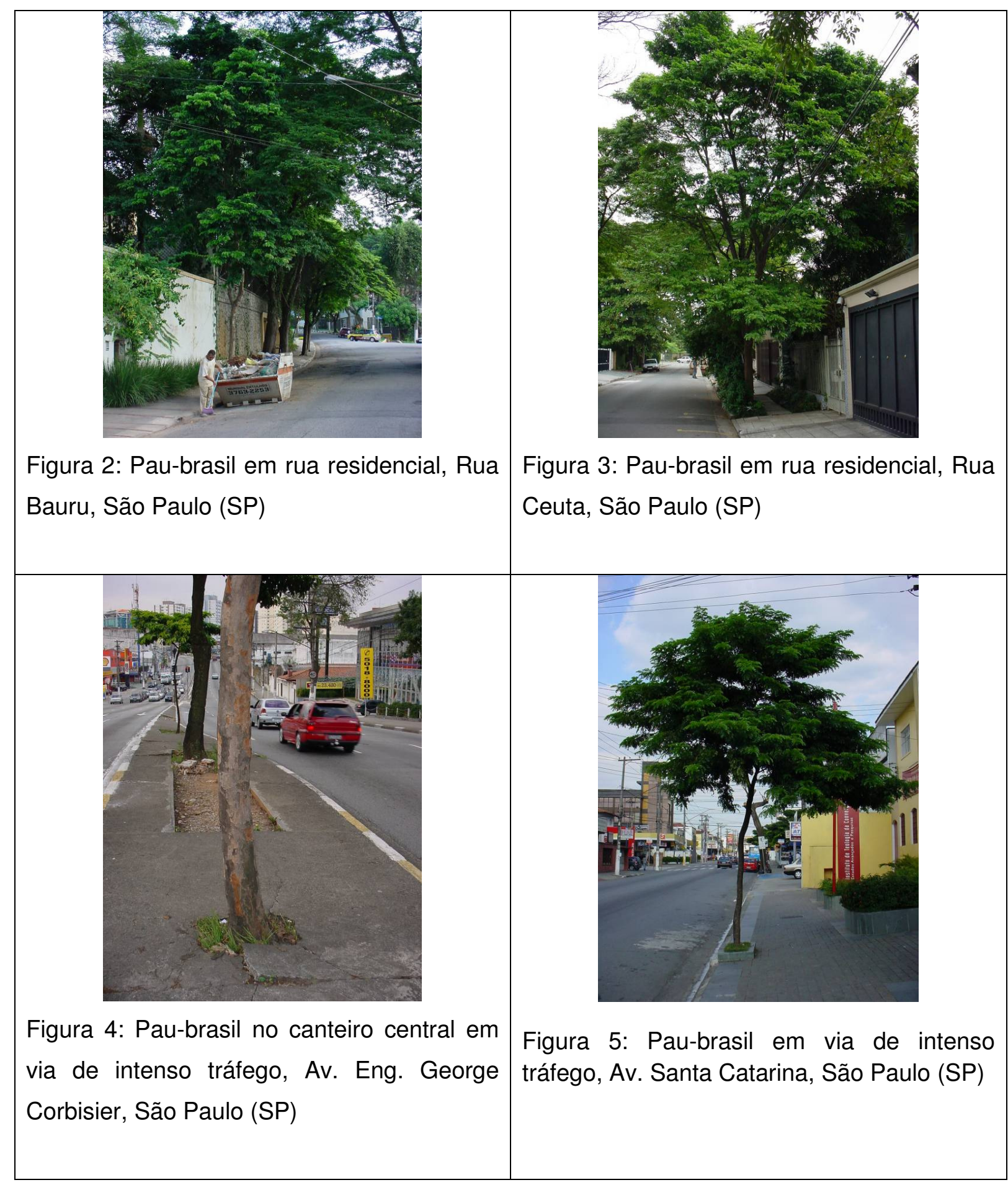

As árvores de pau-brasil, como muitas árvores presentes no meio urbano, também sofrem danos causados pela poluição, podas inadequadas (Figura 6), presença de fiação (Figura 7), inadequação de canteiros (Figura 8) ou conflitos com leito carroçável ou edificação (Figura 9). 


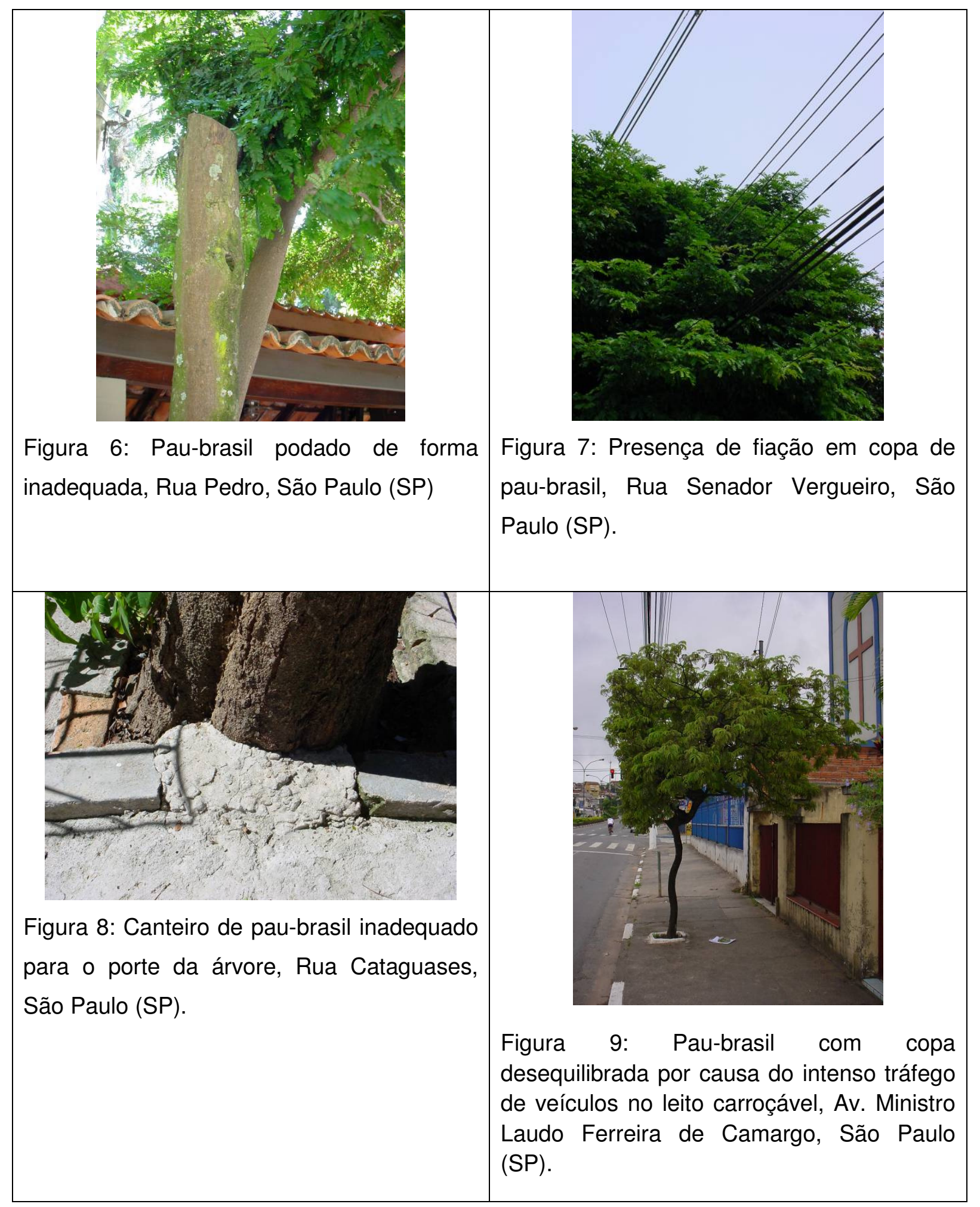

O levantamento sobre a situação atual das árvores de pau-brasil permitiu a formação de um banco de dados detalhado, que poderá contribuir para o manejo adequado dessas árvores e manter sua importância para a conservação ex situ da espécie no meio paulistano.

Um exemplo dessa importância é o pau-brasil considerado "Patrimônio Ambiental da Cidade de São Paulo" pelo Decreto Estadual no 30.443/89 ("Vegetação Significativa do 
Município de São Paulo") existente na Rua dos Zaparás (Figura 10). Este exemplar demonstra que a espécie adaptou-se muito bem às condições climáticas da cidade de São Paulo e, preservadas as condições de seu entorno e manejo ideais para seu desenvolvimento, as árvores podem alcançar grande porte e longevidade.

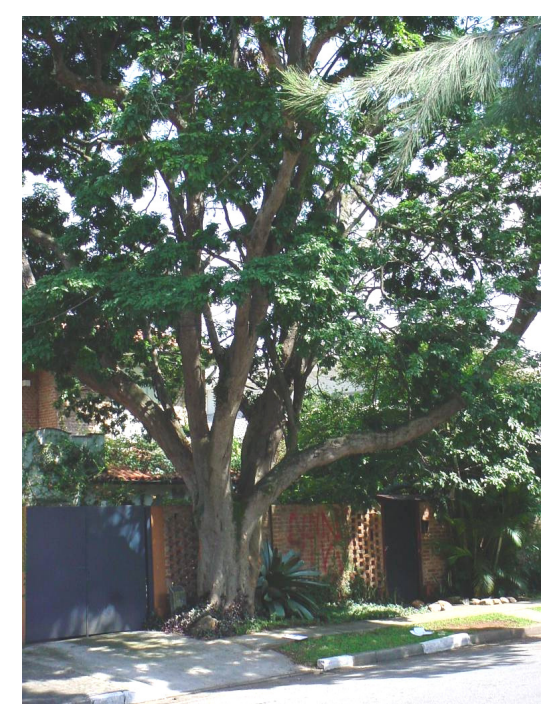

Figura 10: Pau-brasil considerado "Patrimônio Ambiental da Cidade de São Paulo", Rua dos Zaparás, São Paulo (SP)

\section{Rio de Janeiro (RJ)}

Na cidade do Rio de Janeiro, encontraram-se 123 árvores de pau-brasil, distribuídas em vinte logradouros públicos, localizadas nas mais diferentes situações, desde praças, parques, áreas estritamente residenciais até ruas e avenidas de tráfego intenso de veículos:

- Parque Educacional Professor Mello Barreto, Barra da Tijuca - 22059'33,9"S e $43^{\circ} 21$ '37,4"W; altitude = 2m. Encontradas oito árvores de pau-brasil, plantadas em 1995 (o Parque foi inaugurado em 26 de janeiro de 1996). Presença de frutos e flores; altura 4-5m.

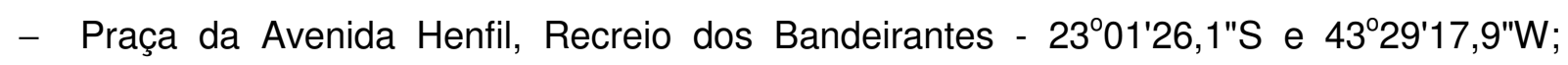
altitude $=2 \mathrm{~m}$. Encontradas 15 árvores de pau-brasil, plantadas em dezembro de 2004, nas falhas da arborização já existente do entorno da praça; altura média de 1,5m.

- Avenida Genaro de Carvalho, Recreio dos Bandeirantes. Encontradas três árvores de pau-brasil, plantadas em setembro de 2002; altura média de 1,5m.

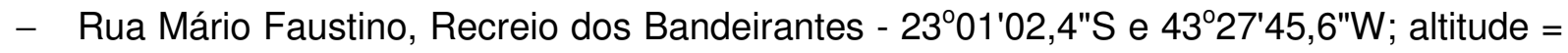
5m. Encontradas três árvores de pau-brasil, plantadas em 2001; altura 2m (Figura 11). 


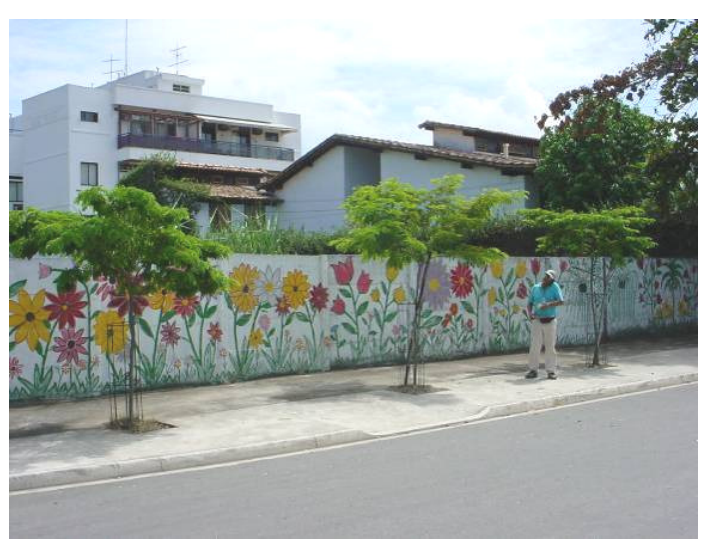

Figura 11: Árvores de pau-brasil, Rua Mário Faustino, Recreio dos Bandeirantes, Rio de Janeiro (RJ)

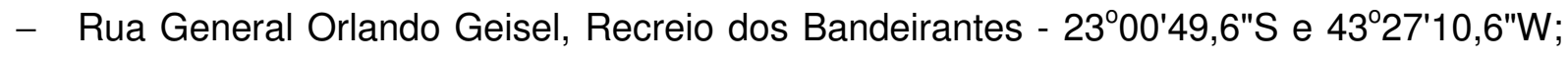
altitude $=8 \mathrm{~m}$. Encontradas quatro árvores de pau-brasil, plantadas em 1999; altura média de $3-4 m$.

- Rua Raul Cunha Ribeiro, 21, Recreio dos Bandeirantes. Encontradas duas árvores de pau-brasil, plantadas em 2003. Presença de flores; altura média de 4m.

- Rua Mapendi X Rua Rodrigues Caldas, Taquara, Jacarepaguá - 2255'23,1"S e $43^{\circ} 22$ '39,1"W; altitude $=38 \mathrm{~m}$. Encontradas duas árvores de pau-brasil, plantadas em julho de 1999. Presença de frutos; altura média de 3-4m.

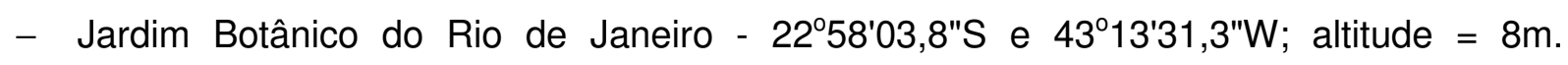
Fotografadas cinco árvores de pau-brasil. Presença de frutos em uma delas (Figura 12).

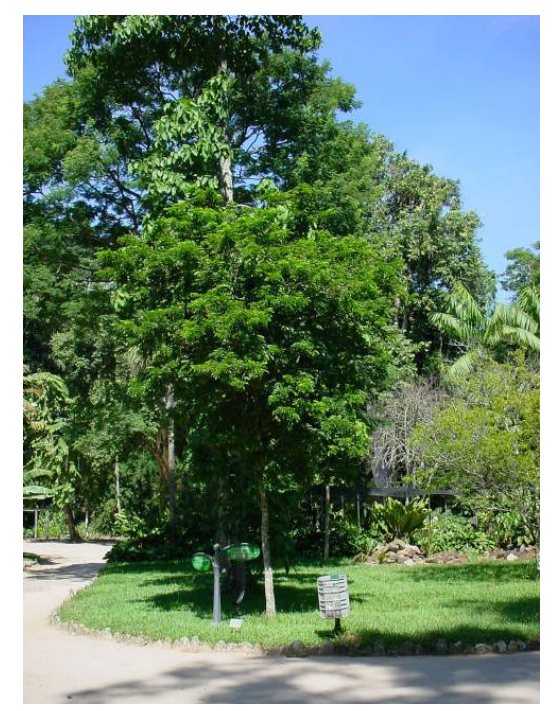

Figura 12: Pau-brasil do Jardim Botânico do Rio de Janeiro, Rio de Janeiro (RJ)

- Instituto Nacional de Educação de Surdos, Rua Laranjeiras, 232, Laranjeiras $22^{\circ} 56^{\prime} 04,2^{\prime \prime S}$ e $43^{\circ} 11^{\prime} 15,4^{\prime \prime} \mathrm{W}$; altitude = 6m. Encontradas duas árvores de pau-brasil; altura média de $3-5 \mathrm{~m}$. 


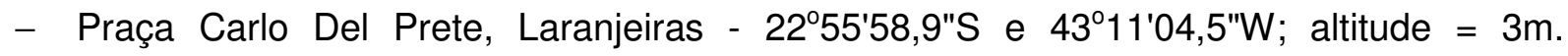
Encontradas sete árvores de pau-brasil; altura média de 2-5m. Presença de frutos em uma delas.

- Rua Laranjeiras, 115, Laranjeiras - $22^{\circ} 55^{\prime} 57,3^{\prime \prime S}$ e $43^{\circ} 10^{\prime} 59,1^{\prime \prime} \mathrm{W}$; altitude = $3 \mathrm{~m}$. Encontrada uma árvore de pau-brasil; altura de $12 \mathrm{~m}$.

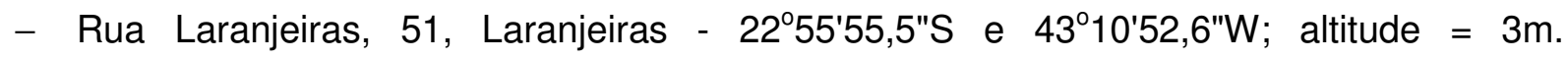
Encontrada uma árvore de pau-brasil; altura de $3 \mathrm{~m}$. Presença de frutos.

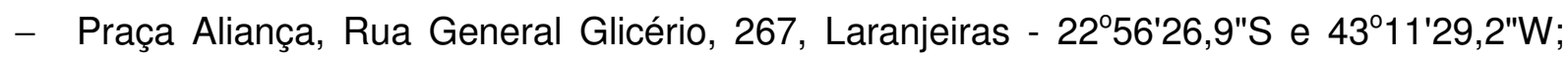
altitude $=8 \mathrm{~m}$. Encontrada uma árvore de pau-brasil; altura de $12 \mathrm{~m}$.

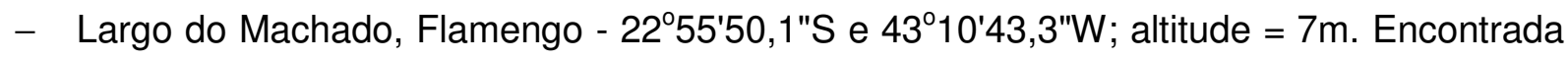
uma árvore de pau-brasil; altura de $5 \mathrm{~m}$.

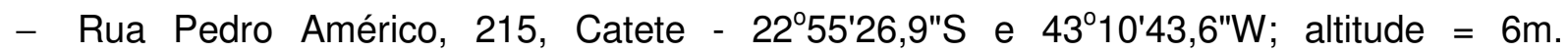
Encontrada uma árvore de pau-brasil; altura de 10m.

- Palácio do Catete, Rua do Catete, 135, Catete/Flamengo - 2255'34,9"S e 43¹0'28,7"W; altitude $=4 \mathrm{~m}$. Encontradas quatro árvores de pau-brasil; altura média de 1,5-5m. Encontradas duas árvores muito parecidas e indicadas pelo funcionário como pau-brasil; era uma leguminosa muito semelhante (Figura 13).

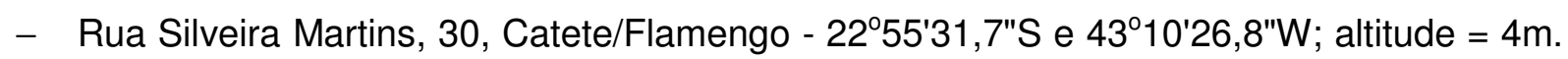
Encontrada uma árvore de pau-brasil, no jardim do edifício; altura de $12 \mathrm{~m}$.

- Próximo à passagem subterrânea do Bar Belmonte e do Teatro de Marionetes, Aterro do Flamengo - $22^{\circ} 56^{\prime} 05,9^{\prime \prime} \mathrm{S}$ e $43^{\circ} 10^{\prime} 23,4^{\prime \prime} \mathrm{W}$; altitude $=3 \mathrm{~m}$. Encontradas 48 árvores de paubrasil; altura média de $12 \mathrm{~m}$.

- Próximo ao estacionamento do Restaurante Porcão Rio's, Aterro do Flamengo $22^{\circ} 56^{\prime} 16,2^{\prime \prime S}$ e $43^{\circ} 10^{\prime} 10,6 \mathrm{~W} \mathrm{~W}$; altitude = 3m. Encontradas nove árvores de pau-brasil; altura média de 1,5-3m. Presença de flores e frutos.

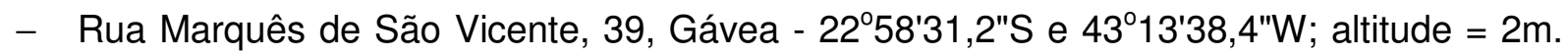
Encontradas três árvores de pau-brasil; altura média de 2-3m.

- Rua Marquês de São Vicente, 19, em frente à Igreja Nossa Senhora da Conceição, Gávea - $22^{\circ} 58^{\prime} 31,2^{\prime \prime S}$ e $43^{\circ} 13^{\prime} 38,4 " \mathrm{~W}$; altitude = 2m. Encontradas três árvores de pau-brasil; altura média de 2-4m (Figura 14). 


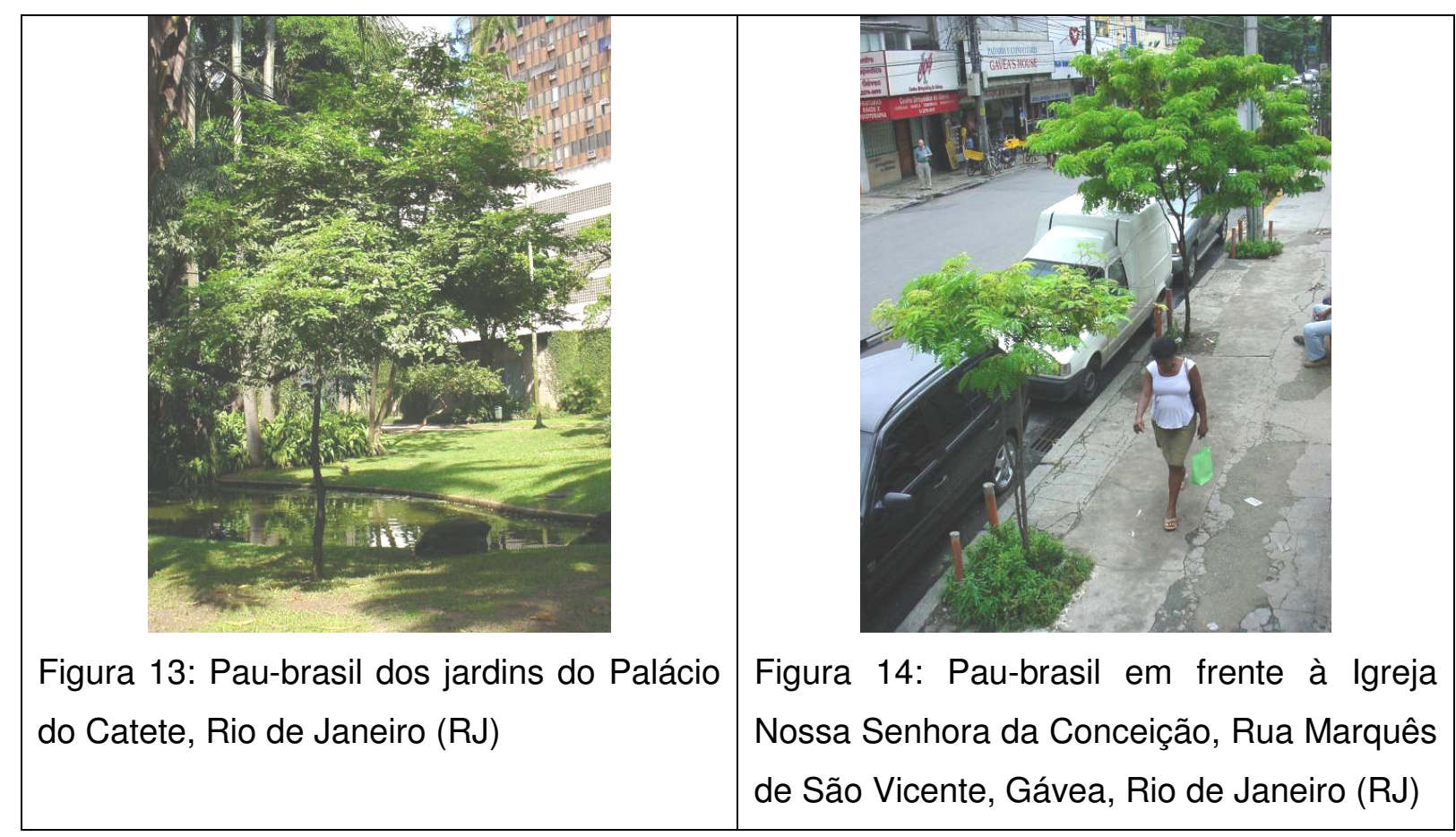

Obtiveram-se, também, as seguintes informações dos técnicos contatados da Fundação de Parques e Jardins (FPJ), Secretaria do Meio Ambiente da Prefeitura Municipal do Rio de Janeiro:

- a FPJ não possui um cadastro ou inventário das árvores presentes na arborização urbana da cidade do Rio de Janeiro, o que é comum ocorrer na grande maioria das cidades brasileiras;

- o pau-brasil não é uma espécie arbórea recomendada para a arborização urbana do Rio de Janeiro, segundo esses técnicos, por causa de seu crescimento lento e por falta de informações quanto ao seu desenvolvimento no meio urbano;

- o pau-brasil é raramente encontrado em ruas do Rio de Janeiro;

- os exemplares de pau-brasil existentes na arborização urbana carioca foram plantados, na maioria das vezes, em comemorações, como o Dia da Árvore, por iniciativa de escolas ou em parques e praças, de acordo com seus projetos paisagísticos.

\section{Recife (PE)}

Em Recife, encontraram-se 67 árvores de pau-brasil, distribuídas em sete logradouros públicos, localizadas nas mais diferentes situações, desde praças, parques e áreas estritamente residenciais até ruas e avenidas de tráfego intenso de veículos:

- Rua Deputado Cunha Rabelo n. 19, Bairro Cidade Universitária - 0802'43,7"S e $34^{\circ} 56 ' 51,1 \mathrm{WW}$; altitude $=33 \mathrm{~m}$. Encontrado um exemplar de pau-brasil. Presença de frutos maduros, altura de $5 \mathrm{~m}$. 
- Praça do Derby, Centro - 08 $03^{\prime} 24,4^{\prime \prime S}$ e $34^{\circ} 54^{\prime} 02,4 " \mathrm{~W}$; altitude = 20m. Encontradas 18 árvores de pau-brasil, em frente ao Quartel do Comando Geral. Presença de flores e frutos maduros e abertos, altura entre 2 e $6 \mathrm{~m}$ (Figura 15).

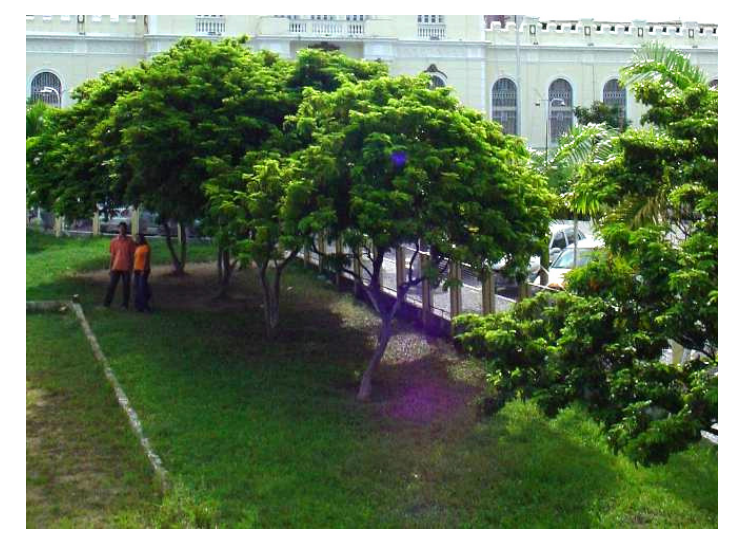

Figura 15: Árvores de pau-brasil, Praça do Derby, Centro, Recife (PE)

- Praça do Derby, Centro - 08 $03^{\prime} 22,5^{\prime \prime S}$ e $34^{\circ} 53^{\prime} 54,5^{\prime \prime}$; altitude $=20 \mathrm{~m}$. Na mesma Praça, perto da Avenida Governador Agamenon Magalhães, encontradas mais três árvores de pau-brasil. Presença de frutos verdes e abertos, altura entre 2 e $3 \mathrm{~m}$.

- Avenida Governador Agamenon Magalhães, Centro - 0803'26,8"S e 3453'52,9"W; altitude $=19 \mathrm{~m}$. Encontradas 21 árvores de pau-brasil, nas proximidades da Praça do Derby, entre a Avenida e o canal central. Presença de frutos maduros, abertos e verdes, com troncos escuros, provavelmente por causa da poluição do intenso tráfego de veículos nessa Avenida; altura entre 4 e $5 \mathrm{~m}$ (Figura 16).

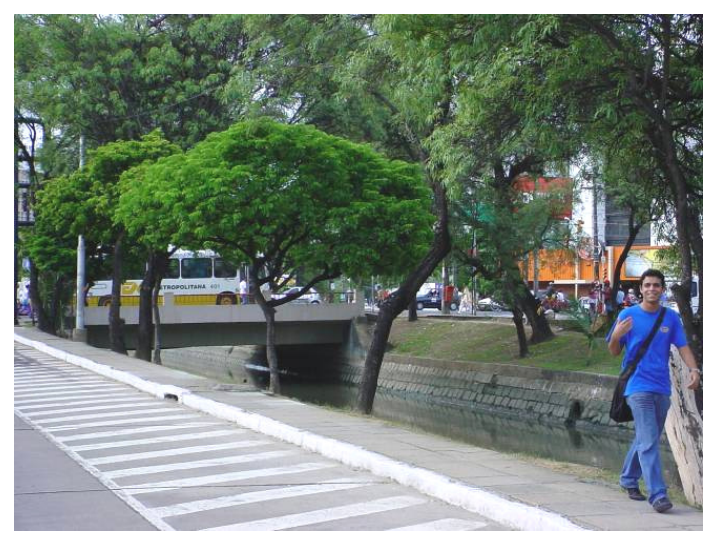

Figura 16: Árvores de pau-brasil, Av. Gov. Agamenon Magalhães, Centro, Recife (PE)

- Praça da Faculdade de Direito da UFPE, Centro - 0803'30,8"S e 3452'55,4"W; altitude $=13 \mathrm{~m}$. Encontradas quatro árvores de pau-brasil. Presença de frutos abertos, altura entre 3 e $5 \mathrm{~m}$.

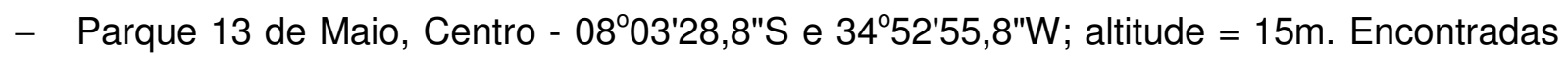
11 árvores de pau-brasil. Presença de flores e frutos verdes e abertos, altura entre 4 e $6 \mathrm{~m}$. 
- Praça da República, Centro - 08 03'41,6"S e 3452'36,6"W; altitude = 13m. Encontradas sete árvores de pau-brasil. Presença de frutos verdes, altura entre 4 e 10m (Figura 17).

- Campo das Princesas, jardins do Palácio da Sede do Governo Estadual, Centro $08^{\circ} 03^{\prime} 34,6^{\prime \prime} \mathrm{S}$ e $34^{\circ} 52^{\prime} 39,8^{\prime \prime} \mathrm{W}$; altitude = $12 \mathrm{~m}$. Encontradas duas árvores de pau-brasil; uma plantada há, aproximadamente, 50 anos e a outra em 1999. Presença de frutos verdes, altura entre 4 e $7 \mathrm{~m}$ (Figura 18).

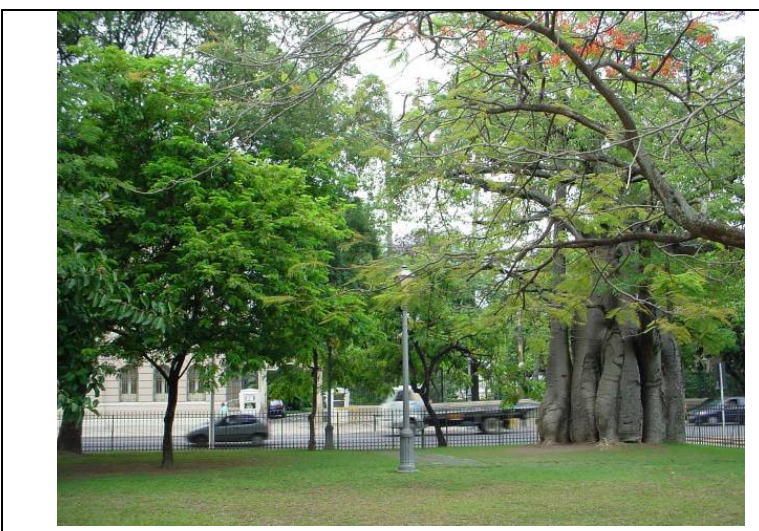

Figura 17: Pau-brasil próximo ao baobá, Praça da República, Centro, Recife (PE).

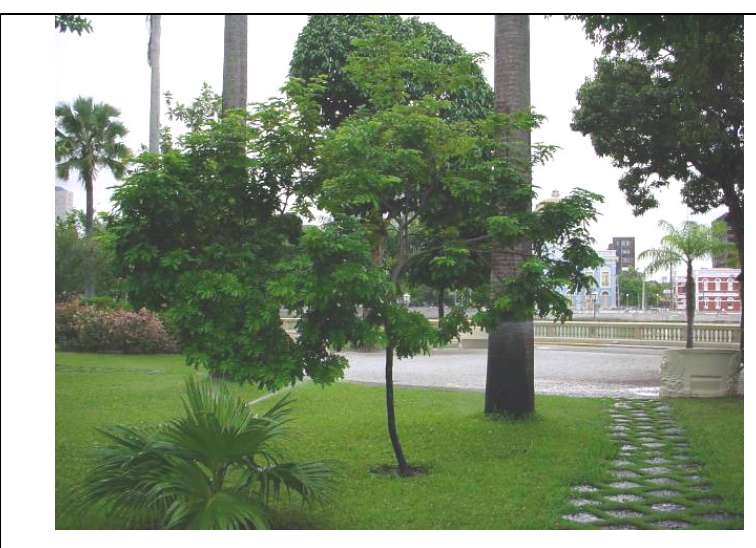

Figura 18: Pau-brasil, Campo das Princesas, Centro, Recife (PE)

Obtiveram-se as seguintes informações com técnicos do Departamento de Praças e Áreas Verdes da Empresa de Limpeza Urbana (Emlurb), da Prefeitura Municipal de Recife, e da Diretoria de Meio Ambiente da Secretaria Municipal de Planejamento, Urbanismo e Meio Ambiente:

- o Departamento de Praças e Áreas Verdes da Emlurb não possui um cadastro ou inventário das árvores presentes na arborização urbana da cidade do Recife, o que é comum ocorrer na grande maioria das cidades brasileiras;

- em Recife, há dois viveiros municipais de produção de mudas: Sementeira do Sítio da Trindade e Sementeira de Dois Irmãos;

- as principais árvores que são recomendadas para plantio são: Bauhinia sp. (pata-devaca), Calliandra brevipes Benth. (escova-de-peru), Thevetia sp. (chapéu-de-napoleão), Lagerstroemia indica L. (resedá), Tecoma stans (L.) Kunth (ipê-de-jardim), Felicium decipiens Thw (felício), Terminalia catappa L. (amendoeira), Tabebuia sp. (ipês), Cassia sp. (cássia-cubana) e Talipariti tiliaceum var. pernambucense (Arruda) Frixell (algodão-depraia);

- o pau-brasil não é uma espécie arbórea recomendada para a arborização urbana do Recife, segundo esses técnicos, por causa de seu crescimento lento, tanto quanto plantado no local definitivo quanto na produção das mudas (leva 3-5 anos para uma muda ficar no porte ideal para plantio); 
- as mudas de pau-brasil são produzidas com sementes vindas as árvores encontradas nas ruas, praças e avenidas e das existentes na própria Sementeira da Trindade, sem a preocupação de elaborar um cadastro de matrizes;

- os exemplares de pau-brasil existentes na arborização urbana de Recife foram plantados, na maioria das vezes, por iniciativa de escolas, quando o munícipe solicita o plantio específico de pau-brasil ou quando projetos de parques escolhem a espécie.

\section{CONCLUSÕES}

O levantamento das informações sobre as árvores de pau-brasil existentes na arborização urbana de São Paulo (SP) permitiu a formação de um banco de dados detalhado, que poderá contribuir para o manejo adequado dessas árvores e manter sua importância para a conservação ex situ da espécie no ambiente urbano paulistano e, para o contato da população com a árvore nacional brasileira.

Também foi possível constatar que as árvores de pau-brasil em ruas e avenidas de tráfego intenso de veículos, na presença de poluentes, parecem ser resistentes às condições adversas do ambiente urbano paulistano. Porém, em experimentos com plantas jovens de pau-brasil expostas à poluição em locais da cidade de São Paulo, BULBOVAS (2005) constatou que "a espécie é suscetível à condição atual de contaminação atmosférica da cidade de São Paulo, não sendo recomendada para uso na ornamentação urbana”.

No Rio de Janeiro (RJ), constatou-se o maior número de árvores de pau-brasil na arborização urbana, que também se apresentam adaptadas às condições adversas no ambiente urbano, embora Rio de Janeiro e Recife sejam cidades com menor poluição atmosférica quando comparadas com São Paulo.

Em Recife (PE), constatou-se o segundo número de árvores de pau-brasil presentes na arborização urbana, que também estão adaptadas às condições ambientais urbanas. Porém, esperava-se o contrário uma vez que Pernambuco tem um histórico importante de ações efetivas para a conservação da espécie, tais como a existência da Estação Ecológica de Tapacurá, criada em 1975, e da Fundação Nacional Pau-brasil, criada em 1988.

Em relação ao número de árvores registradas, não se pode comparar os resultados obtidos em São Paulo com aqueles obtidos no Rio de Janeiro e em Recife, visto que as metodologias de coleta de dados foram diferentes. Porém, pode-se verificar um maior uso do pau-brasil na arborização urbana do Rio de Janeiro e de Recife do que em São Paulo.

\section{AGRADECIMENTOS}


À Fundação de Amparo à Pesquisa do Estado de São Paulo (Projeto Temático Paubrasil, Processo 00/06422-4), pelo financiamento da pesquisa. Aos estagiários, técnicos e funcionários das instituições participantes da pesquisa e das instituições que contribuíram com informações e dados sobre a utilização do pau-brasil na arborização urbana das cidades pesquisadas.

\section{REFERÊNCIAS}

BRASIL, Helena Maria Silva. Caracterização da arborização urbana: o caso de Belém (PA). 1994, 204p. Dissertação (Mestrado em Ciências Biológicas) - Universidade Federal do Pará, 1994.

BULBOVAS, Patrícia. Defesas antioxidativas em plantas jovens de Caesalpinia echinata Lam. (pau-brasil) como indicadoras de resistência da espécie à poluição atmosférica na cidade de São Paulo (SP). 2005, 108p. Tese (Doutorado em Ciências Biológicas) - Instituto de Biociências, Universidade de São Paulo, Piracicaba, 2005.

CAVALHEIRO, Felisberto. Urbanização e alterações ambientais. In: TAUK, Sâmia Maria (Org). Análise ambiental: uma visão multidisciplinar. São Paulo: Edunesp. 1991. p.8899.

FRANKEL, O. H. \& SOULÉ, M. E. Conservation and evolution. Cambridge: Cambridge University Press, 1992.

HOEHNE, Frederico Carlos. Arborização, parques e jardins e a cidade de Santos. In:

Relatório Anual do Instituto de Botânica. São Paulo: Secretaria de Agricultura, Indústria e Comércio, 1943. p 89-96.

LIMA, Ana Maria Liner Pereira. Piracicaba/SP: análise da arborização viária na área central e em seu entorno. 1993, 238p. Tese (Doutorado em Solos e Nutrição de Plantas) Escola Superior de Agricultura "Luiz de Queiroz", Universidade de São Paulo, Piracicaba, 1993.

MELLO FILHO, Luiz Emydio de. Burle Marx e arborização urbana. Boletim Informativo da Sociedade Brasileira de Arborização Urbana, Rio de Janeiro, v. 8, n. 2, p. 3, abr./maio/jun. 2000. 
MILANO, Miguel Serediuk. Avaliação e análise da arborização de ruas de Curitiba/PR. 1984, 130p. Dissertação (Mestre em Ciências Florestais) - Universidade Federal do Paraná, Curitiba, 1984.

RAVEN, P. R. Ethics and attitudes. In: SIMMONS, J. B. et al. (Eds). Conservation of threatened plants. New York: Plenum Press, 1976. p.155-179.

ROCHA, Yuri Tavares. Conservação do pau-brasil (Caesalpinia echinata Lam.

Leguminosae). In: CONGRESSO DA SOCIEDADE BOTÂNICA DE SÃO PAULO, 15, 2004a, Ubatuba/SP. Anais... Ubatuba: Sociedade Botânica de São Paulo/Universidade de Taubaté, 2004a. (CD-ROM)

ROCHA, Yuri Tavares. Ibirapitanga: história, distribuição geográfica e conservação do pau-brasil (Caesalpinia echinata Lam., Leguminosae) do descobrimento à atualidade. 2004b, 398p. Tese (Doutorado em Ciências) - Departamento de Geografia, Faculdade de Filosofia, Letras e Ciências Humanas, Universidade de São Paulo, Piracicaba, 2004b.

ROCHA, Yuri Tavares. Distribuição geográfica do pau-brasil (Caesalpinia echinata Lam. Leguminosae). In: SIMPÓSIO BRASILEIRO DE GEOGRAFIA FÍSICA APLICADA, 11, 2005, São Paulo/SP. Anais... São Paulo: Departamento de Geografia/FFLCH/USP, 2005. p. 33203331.

ROCHA, Yuri Tavares; PRESOTTO, Andrea; FREITAS JUNIOR, Gerson; CAVALHEIRO, Felisberto. Conservação ex situ de pau-brasil (Caesalpinia echinata Lam., Leguminosae) no estado de São Paulo. In: CONGRESSO DE ECOLOGIA DO BRASIL, 6, 2003, Fortaleza/CE. Anais... Fortaleza: Editora da Universidade Federal do Ceará, 2003. v. 1. p. 314-316.

RODRÍGUEZ-AVIAL LLARDENT, Luis. Zonas verdes y espacios libres em la ciudad. Madrid: Instituto de Estudios de Administración Local, 1982. 539p.

SÃO PAULO (Estado). Vegetação Significativa do Município de São Paulo. São Paulo: Secretaria do Estado do Meio Ambiente/Secretaria Municipal de Planejamento, 1998.

TERRA, Carlos Gonçalves; ANDRADE, Rubens de; TRINDADE, Jeanne; BENASSI, Alfredo (Coord.). Arborização: ensaios historiográficos. Rio de Janeiro: EBA/UFRJ, 2004, 215p. 